\title{
The analysis of ice can structure forms of ice block machine impacting on flow field of ice tank
}

\author{
Lili She ${ }^{1, a}$, Qinghai Luo ${ }^{1, b}$ and Bingjie Mi ${ }^{1, \mathrm{c}}$ \\ ${ }^{1}$ School of Urban Construction, University of South China \\ Hengyang 421001, China \\ a13789373719@163.com, b673808769@qq.com, ${ }^{\mathrm{c}} 2323075462 @ q q . c o m$
}

Keywords: CFD; ice can; ice tank; heat transfer

Abstract. CFD modeling method was applied on simulation analysis for ice can structure impacting on flow field of ice tank in this article. The cross section of existing ice cans was rectangular structure. Velocity between frontal side and lee side of ice cans was close to zero, fluid resistance was large. Contrast simulation results of three different kinds of ice cans A, B, C showed that using the circular-arc structure ice cans lowered fluid resistance and uniformed velocity distribution and enhanced heat transfer efficiency remarkably.

\section{Introduction}

Ice block machine was an indirectly ice making system, in which ice cans were setting in low temperature brine tank. Water in ice cans was turn into ice finally with salt water which was used as secondary refrigerant bringing its heat off. Ice cans were made into cuboid, the upper cross-sectional area was larger than the bottom, this kind of structure helped ice demould from ice cans easily. Ice was hard in density and uneasy to melt, it was stored and transported easily[1]. At present, ice block machine was still the dominating ice-making equipment in fisheries. Compared with directly ice-making equipment, block ice machine was short in ice-making efficiency and consumed a large amount of energy.

Scholars at home and aboard have done some research on the optimization of ice machines. For example, Jiantao Zhan introduced 3D modeling and engineering graphics technology in design of ice machine products [2]. Fluent software was used in simulation process. Peng Guan studied on how to improve the evaporator of ice machines. Improved methods were moving off fluid supply header from middle side on the top of evaporator and getting rid of gas return header, then connected it to main pipe of refrigerant tube bundles[3]. Youming Zhuang put forward the saving methods of ice making process, such as using special supercooler and supercooling compressor to precool raw water[4]. Cengyi Lv proposed some ways to improve ice machine, for example, taking out all the bars, increasing the surface area of ice cans, lowering salt water temperature and reducing the thickness and increasing the height of ice cans[5]. Lirong Qiu put other ways to improve ice machines, for instance, moving gas return header to the back-end of evaporator, increasing area of evaporator and adding an agitator [6].

Scholars all over the world have put lots of good ways to improve ice machine. However, the research in improving flow field by using software CFD was very rare. In this paper, flood velocity, temperature and pressure distribution of tank made of the existing ice cans and two improved ice cans were compared. After comparison, some good ways to perfect flow field were proposed.

\section{Ice block machine parameters}

The sample of ice block machine was taken from Guangzhou Icesource Refrigeration Equipment Co.,Ltd (CBFI)[7]. This type of ice block machine was named as BBI10-30 and its daily output was $10 \mathrm{t} / \mathrm{d}$. It was made from ice cans, evaporator and agitator. Supply water temperature was $23^{\circ} \mathrm{C}$, the block ice ultimate temperature was $-8^{\circ} \mathrm{C}$, salt water temperature was $-10^{\circ} \mathrm{C}$, the evaporation temperature was $-15^{\circ} \mathrm{C}$, weight of an ice can of block ice was $30 \mathrm{~kg}$. Size of upper surface of ice can was $300 \times 120 \mathrm{~mm}$, size of bottom surface of ice can was $280 \times 120 \mathrm{~mm}$, height was $1100 \mathrm{~mm}$, thickness 
of ice cans wall was $1.5 \mathrm{~mm}$. Quantity of ice cans was 168 , ice cans arrayed 8 row and 21 column. Size of ice block machine was $8280 \times 1420 \times 1250 \mathrm{~mm}$. The type of agitator is LJ340, rotate speed was 960r/min, impeller diameter was $340 \mathrm{~mm}$, the power was $4 \mathrm{kw}$.

\section{The geometric structure of existing ice cans and the improved ones}

To simplify the model, the salt water was assumed velocity kept constant when it flow into the ice tank through the blender and ignore the influence of gravity, besides, the model was simplified to the two-dimensional situations. On which case the flow field was distributed on plane coordinate. Fig. 1 reflects the cross section of three different ice can forms. Fig. 1(a) shows the cross section of ice cans of Type A, the frontal side of ice cans of Type A was vertical to inflow. Fig. 1(b) shows the cross section of ice cans of Type B, the frontal side of ice cans of Type B was circular-arc. Fig. 1(c) shows the cross section of ice cans of Type $\mathrm{C}$, frontal side had a certain angle to inflow. The volume of the three ice cans was unchanged, which meant ice-making capacity of ice block machine remaining the same.

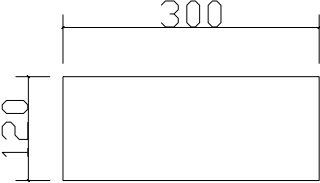

(a)

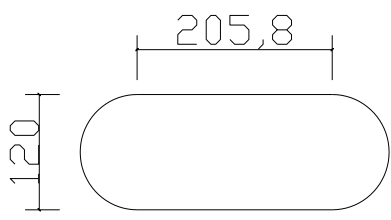

(b)

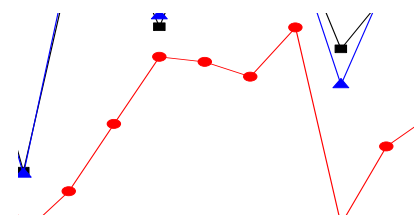

(c)

Fig. 1. The cross section of three different ice can forms(Unit, mm)

\section{Parameter settings of ice tank numerical simulation}

Analysis of salt water flow field of ice tank by CFD was based on mass conservation equation, momentum conservation equation and energy conservation equation. In order to draw high quality grid, grid mesh type was set as Tri, gird mesh way was set as Pave, grid internal size was set as $6 \mathrm{~mm}$. Salt water of ice tank was a kind of incompressible flood, chose Pressure Based Implicit Solver, chose $\mathrm{K}$-epsilon(2eqn) turbulence flow model. When the initial temperature of salt water was $-10^{\circ} \mathrm{C}$, density of salt water was $1175 \mathrm{~kg} / \mathrm{m}^{3}$, specific heat capacity of salt water was $3315 \mathrm{~J} / \mathrm{kg} \bullet \mathrm{k}$, dynamic viscosity coefficient of salt water was $0.004704 \mathrm{~kg} / \mathrm{m} \cdot \mathrm{s}$, thermal conductivity coefficient of salt water was $0.505 \mathrm{w} / \mathrm{m} \bullet \mathrm{k}$. Residual Convergence Criterion was le-5.

Boundary conditions were sat as follows:

Velocity inlet: It was shown on Fig. 2. Entrance average velocity was got from rotational speed of agitator.

$$
v=\omega \times \gamma
$$

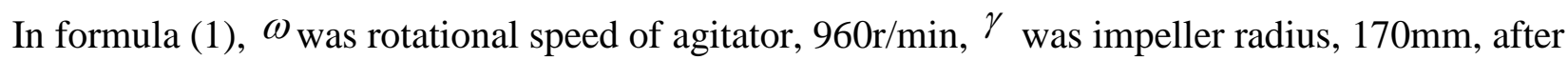
calculation, $v$ was $17.0816 \mathrm{~m} / \mathrm{s}$. Outflow: it was shown on Fig. 2. It was free outflow. Ice cans wall: The temperature of ice cans wall was $265 \mathrm{~K}$.

\section{The analysis and comparison of the three different ice can forms}

The research on velocity field distribution and temperature distribution field of three forms was made by employing the software Tecplot. It formed a line figure by selecting scattered points. The middle positional value between the tenth and the eleventh column ice cans was used as the $\mathrm{X}$ value. At the same time, the $\mathrm{Y}$ values were $0.1,0.2,0.3,0.4,0.5,0.6,0.7,0.8,0.9,1,1.1,1.2$, 1.3, 1.4. The plane structure graph of ice tank constitute with the rectangular structure ice cans was shown in Fig.2. 
The velocity, temperature and pressure distribution nephogram were got from Fluent. The velocity and temperature values of these points were got from importing the Fluent date into

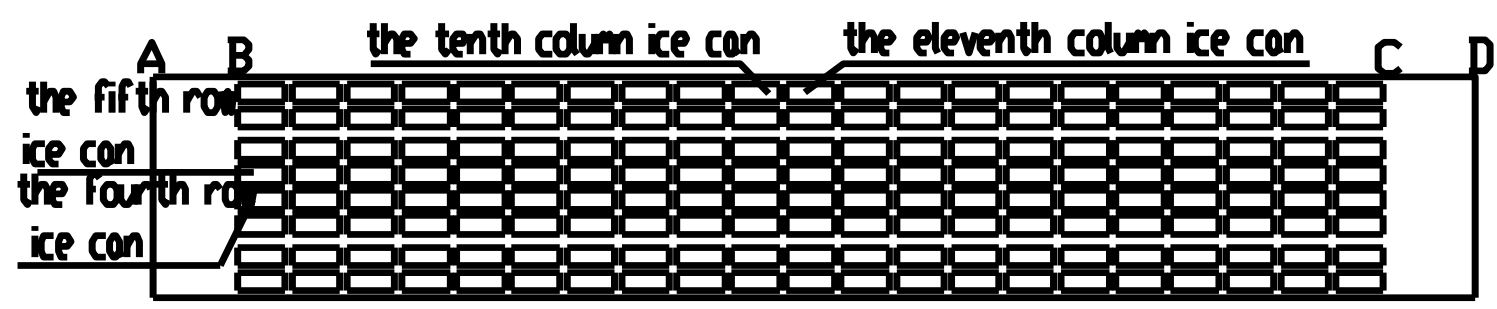

Fig. 2. The plane structure graph of ice tank constitute with the rectangular structure ice cans software Tecplot. The comparison of velocity value of three ice tanks with three different ice cans in middle position of tenth column and eleventh column was shown in Fig. 3. Flow field of ice tank made of ice cans of Type A was named case1, those of Type B was named case2, those of Type C was named case3. Fig. 3 indicates that the velocities of salt water were very inhomogeneous on these positions of case 1 and case 3 , the velocity were closed to zero in the middle positive of frontal aide and lee side of ice cans. Nevertheless, the velocities on those positions of case 2 were more homogeneous, and the velocities closing to zero appear rarely. Results indicated that the salt water velocity distribution of case 2 was more uniform.

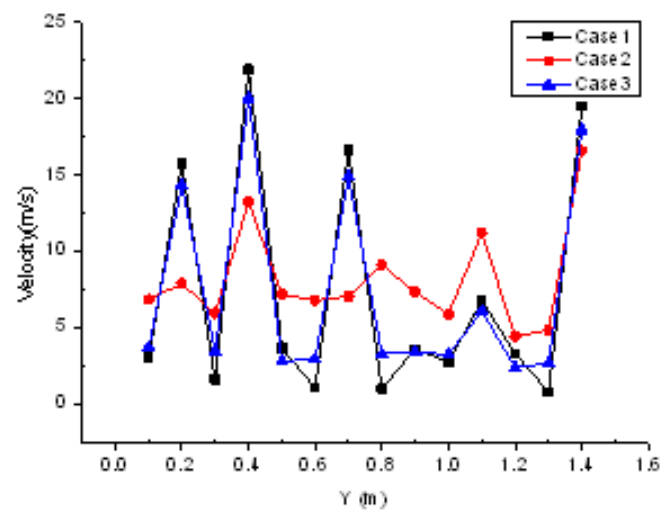

Fig. 3. The velocity comparison where $\mathrm{x}$ was middle value between tenth and eleventh column ice can

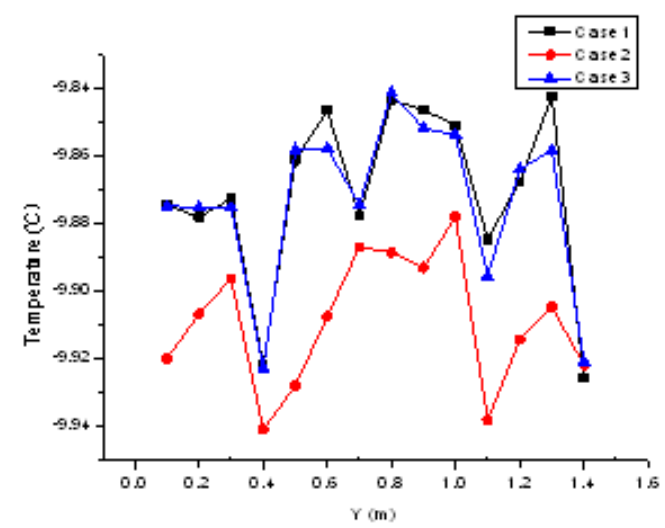

Fig. 4. The temperature comparison where $\mathrm{x}$ was middle value between tenth and eleventh column ice can

The comparison of temperature value of three ice tanks with different ice cans in middle position of tenth column and eleventh column was shown in Fig. 4. The figure reflects that the salt water temperature rising faster in case 1 and case3, compared to case2. Obviously, the salt water absorbed more heat in case 1 and case 3 . It was concluded that the structure of case 1 and case 3 behave greater in heat transfer effect.

The middle positional value between the fourth row and the fifth row ice cans were used as the $\mathrm{Y}$ value. $Y$ was $0.71 \mathrm{~m}$. At the same time, the $X$ values were $0.5,1,1.5,2,2.5,3,3.5,4,4.5,5,5.5,6,6.5$, $7,7.5,8$. The velocity and temperature values of these points were got from importing the Fluent date into Import the Fluent date of these points into software Tecplot. The comparison of temperature value of three ice tanks with different ice cans in middle position of fourth row and the fifth row ice cans was shown in Fig. 5. As shown in Fig. 5,when the Y value was $0.71 \mathrm{~m}$, the salt water of case1 had a faster velocity than case 3 that had a faster velocity than case2. But, the velocities of the three forms all showed a trend of decline at $\mathrm{Y}$ direction. The fluid velocity of case 2 had a larger fluctuation, which indicated that the fluid field of case 2 had obtained a greater disturbance.

The temperature comparison among the three forms of ice cans on these positions where the $Y$ value was $0.71 \mathrm{~m}$ was shown in Fig. 6 . The figure reflected that the salt water had lower temperature in case 1 , compared to case 2 and case 3 . Obviously, the salt water absorbed more heat in case 2 and case 3 . So we concluded that the structure of case 2 and case 3 behave better in heat transfer effect. 
Based on calculation of Fluent, results indicated that the pressure drop between the entrance and the exit of case 1 was $914.5 \mathrm{kPa}$, while the case 2 was $569.6 \mathrm{kPa}$, and the case 3 was $814.8 \mathrm{kPa}$. It showed that the case 2 and the case 3 had a lower fluid resistance.

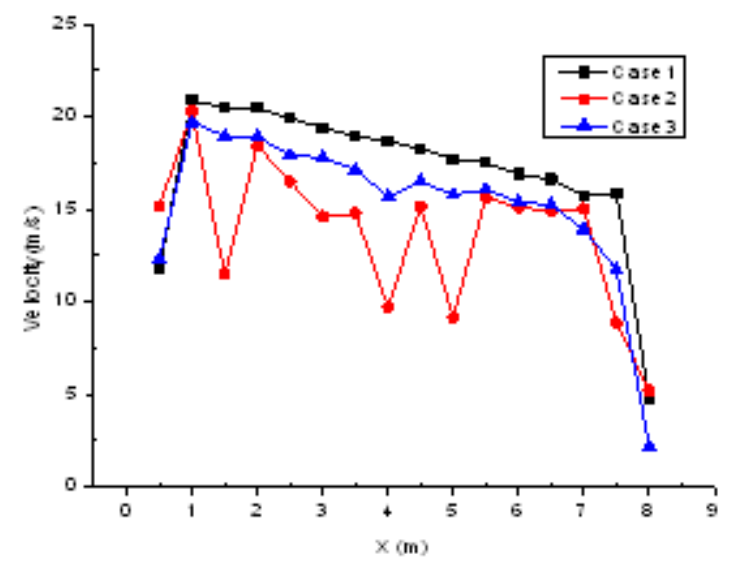

Fig. 5. The velocity comparison where the $Y$ value was $7.1 \mathrm{~m}$

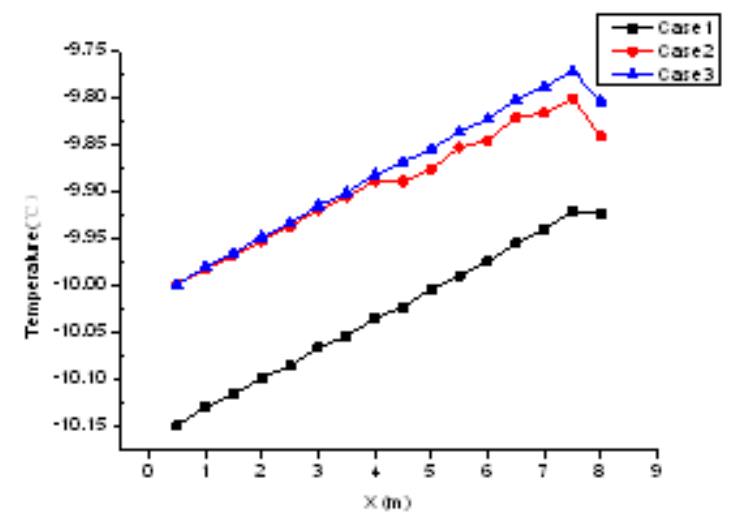

Fig.6. The temperature comparison where the $\mathrm{Y}$ value was $7.1 \mathrm{~m}$

\section{Conclusions}

CFD modeling method was used on simulation analysis for ice can structure impacting on flow field of ice tank, the following conclusions were obtained from simulated results.

(1) Salt water velocity of ice tank made of ice cans of Type A and Type C between frontal side and lee side was close to zero. However, for the ice tank made of ice cans of Type B, the salt water velocity distribution of ice cans was uniform on the $\mathrm{X}$ axis, while the velocity distribution on the $\mathrm{Y}$ axis fluctuated remarkably. Circular-arc structure of ice cans enhanced fluid disturbance of ice tank, so the velocity distribution of salt water was more uniform.

(2) Salt water temperature of ice tank made of ice cans of Type A and Type C changed greatly on the $\mathrm{X}$ axis, while it changed greatly on the $\mathrm{Y}$ axis where the ice tank was made of ice cans of Type $\mathrm{B}$ and Type C. Salt water of ice tank made of ice cans of Type C took more heat away, that enhanced heat transfer effect.

(3) Pressure drop between the entrance and the exit of salt water of ice tank made of ice cans of Type B and Type C was lower than that of Type A. Fluid resistance of ice tank made of two kinds of improved ice cans was less than the existing ice cans.

\section{Acknowledgements}

This work was financially supported by a Scientific Research Fund of Hunan Provincial Education Department(13C329), and a Scientific Research Fund of Hengyang Chengdu Science and Technology Bureau(2011KS19)

\section{References}

[1] X.D. Zheng: Refrigeration and principle(Mechanical industry Publications, China 2011)

[2] J.T. Zhang: The application of 3D modeling and engineering graphics technology in ice machine products design-living example introduce of design and research on export ice machine. Modern Machinery. Vol. 1(2005), p.32

[3] P. Guan: Improvement and analysis on evaporator of ice tank. Refrigeration. Vol. 24(2005), p.71

[4] Y.M. Zhuang: Energy saving methods of salt water ice-making process. Journal of Shanhai fisheries university. Vol. 11(2002), p.295

[5] L.Y. Ceng: The improvement of ice tank. Refrigeration. Vol. 19(2000), p.82 
[6] L.R. Qiu: An example for the improvement of ice tank. Refrigerate technique. Vol. 2(1997), p.37

[7] Information on http://www.icemakerchina.com 